Louis Pasteur

Q

143

P2L6 



\section{DUIS PASTEIR}

$1822-1922$

NEDERLANDSCHE HERDENKING 


$$
\begin{aligned}
& Q \\
& 143 \\
& P_{2} L 6
\end{aligned}
$$

IIBRARY

APR 31967 

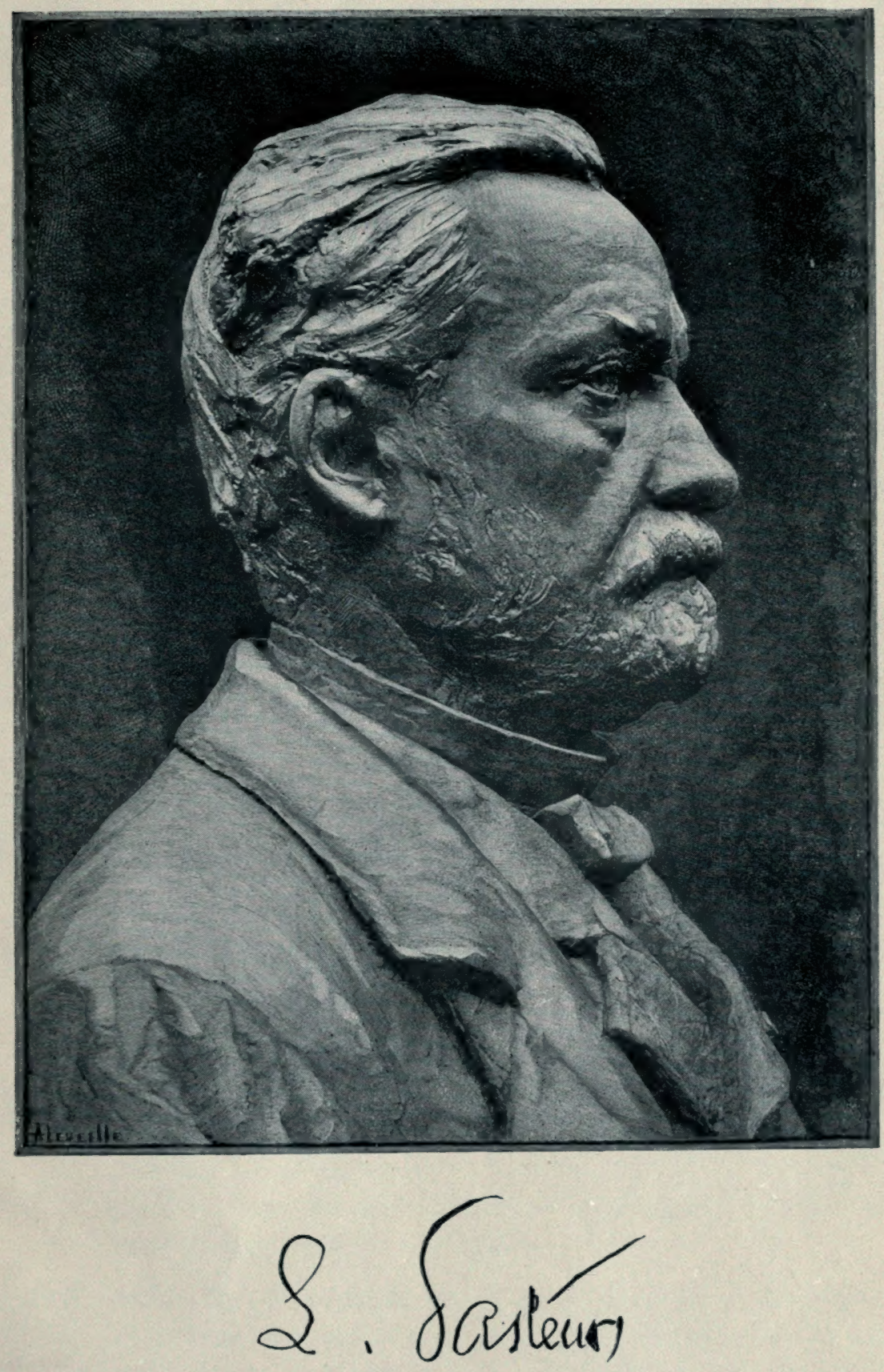



\section{Ter herinnering aan Pasteur's Levenswerk.}

1822 (27 December). Geboren te Dôle.

1842-1847 Studiejaren te Parijs

1848 Onderzoekingen over de betrekkingen, die kunnen bestaan tusschen den kristalvorm, de scheikundige samenstelling en de richting, waarin het polarisatievlak kan worden gedraaid.

Scheiding van het druivenzuur in "linksch" en "rechtsch" wijnsteenzuur door uitzoeken der verschillend-asymmetrische kristallen.

1849 Hoogleeraar in de scheikunde aan de Universiteit te Straatsburg.

Erkenning van de moleculaire asymmetrie als eigenschap van natuurlijke organische stoffen.

1853 Scheiding van het druivenzuur in linksch en rechtsch wijnsteenzuur met behulp van een andere asymmetrische (natuurlijke organische) stof.

1854 Hoogleeraar in de scheikunde en deken der faculteit te Rijssel.

1855 Onderzoekingen over amylalcoholen,

1857 over melkzuurgisting,

1857 over alcoholische gisting.

1857 Administrateur der école normale supérieure te Parijs.

1858 Over gisting van wijnsteenzuur.

Gisting blijkt niet een zuiver scheikundig proces, waarbij moleculen van eiwitachtige stoffen tot ferment worden, (Liebig) maar verschijnsel van het bestaan en de voortplanting van kleinste levende wezens in de betreffende voor gisting vatbare vloeistoffen.

1860-1862 Eerste proeven over de zoogenaamde generatio spontanea (van-zelf-ontstaan van het levende uit doode stof). Deze en latere proeven bevestigen de mogelijkheid 
van generatio spontanea niet: een voor bederf vatbare vloeistof (bouillon, enz.) waarin door koken al het levende wordt gedood, bederft niet, ook niet door aanraking met lucht, indien zij slechts tegen levende kiemen van buitenaf wordt beschermd.

1861 Onderzoekingen over boterzuurgisting.

Door de vondsten van mikroben als oorzaken van gistingsprocessen verschijnen vroegere waarnemingen over mikroben bij ziekte in een ander licht; ziekte werd n.l. veelal als gisting beschouwd. De leer der besmettelijke ziekten vangt hiermee een nieuw tijdperk aan. (DAVAINE). Van PASTEUR's-proeven over gisting is ook LISTER uitgegaan bij zijn pogingen tot afweer van kiemen uit de lucht bij heelkundige operaties; de heelkunde opent daarmee een nieuw tijdperk; dat der antiseptiek.

1861-1862 Over azijnzuurgisting en azijnzuurfabricatie.

1863 Onderzoekingen over rotting.

1863-1864 Onderzoekingen over bereiden en bewaren van wijn.

1865 e. v. Bestrijding van de ziekten der zijdewormen.

1867 Nota aan NAPOLEON III over de noodzakelijkheid een instelling te scheppen geschikt tot proefondervindelijk onderzoek van besmettelijke ziekten.

1871 Over bereiden en bewaren van bier.

\section{Lid der Académie de Médecine.}

1873 Samenwerking met den chirurg AlPH. GuÉRIN tot verbetering van de heelkundige techniek.

\section{4 „Récompense nationale."}

1875 e. v. Strijd in en buiten de Académie de Médecine tegen de verdedigers van de leer der spontane wording van besmettelijke ziekten.

1876 Kweeken van ziektekiemen - miltvuur, kippecholera op kunstmatige kweekgronden, zooals bouillon, e. a. voor bederf-vatbare vloeistoffen. 
1878-1879. Kweeken van mikroben uit etter, beenmergontsteking en kraamvrouwenkoorts.

1879 e. v. Vondsten op het gebied van "vaccinatie”. Oude culturen van kippecholerabacillen, ingespoten bij kippen, bleken aan deze dieren een verhoogden weerstand te hebben gegeven tegen virulente kiemen van dezelfde soort.

PASTEUR vergeleek dit verzwakte virus met de koepokstof, het „vaccin” dat behoedt tegen besmetting met echte pokken.

1880 "Vaccin” tegen miltvuur.

1881 Begin der onderzoekingen over hondsdolheid.

1882 "Vaccin” tegen vlekziekte der varkens.

1882 Lid der Académie Française; den zetel innemend van Littré; discours de réception beantwoord door Ernest Renan.

1883 Récompense nationale.

1884 Bescherming van honden tegen hondsdolheid door behandeling met een op een bepaalde wijze verzwakt virus (uit konijn).

1885 Behandeling van JosepH MeIsTer, twee dagen voor de aanmelding door een dollen hond ernstig gebeten.

1887 Uitgave der Annales de l'Institut Pasteur.

1888 Plechtige opening van het Institut Pasteur.

1892 Huldiging ter gelegenheid van den 70 sten verjaardag.

1895 (28 September). Overlijden. 


\section{Nederlandsche Herdenking van Louis Pasteur 1822-1922.}

\section{De Nederlandsche Maatschappij tot Bevordering der Geneeskunst heeft}

DR. H. AldershofF . . . . . . . . . . . . . Utrecht, Prof. Dr. M. W. Beyerinck . . . . . . . . . Gorsel, PRof. DR. L de BlieCK . . . . . . . . . . . Utrecht, Dr. C. W. Broers . . . . . . . . . . . Utrecht, Prof. Dr. C. EiJKMan *. . . . . . . . . . Utrecht, Prof. P. C. Flu . . . . . . . . . . . . . . Leiden, Prof. DR. L. van Itallie . . . . . . . . . . . Leiden, Prof. Dr. F. M. JAEger . . . . . . . . Groningen, DR. H. KlinKERT . . . . . . . . . . . . Rotterdam, Prof. Dr. A. J. Kluyver . . . . . . . . . . . Delft, Prof. A. Klein . . . . . . . . . . . . . Groningen, Prof. Dr. J. J. van Loghem . . . . . . . . Amsterdam, Prof. Dr. W. Nolen. . . . . . . . . . . . Leiden, Prof. Dr. J. Poels . . . . . . . . . . . Rotterdam, Prof. Dr. R. H. Saltet . . . . . . . . . Amsterdam, Prof. Dr. N. L. Söhngen . . . . . . . . . Wageningen, Prof. Dr. C. H. H. Spronck. . . . . . . . . Utrecht, Prof. Dr. N. H. Swellengrebel . . . . . Amsterdam, Dr. F. G. Waller.

Prof. Dr. Johanna Westerdijk. . . . . . . . Utrecht, ARTS L. K. WolfF . . . . . . . . . . . Amsterdam,

uitgenoodigd een comité te vormen tot voorbereiding van een Nederlandsche herdenking van PASTEUR's geboorte vóór honderd jaren. Dit comité werd geinstalleerd door den toenmaligen voorzitter der Maatschappij DR. H. KLinkERT, op 11 Maart 1922.

Dit comité koos zich een uitvoerend comité bestaande uit:

Prof. Dr. J. J. van Loghem, Voorzitter.

Dr. H. Aldershoff, Onder-Voorzitter.

ARts L. K. WolfF, Secretaris-Penningmeester.

Prof. P. C. Flu.

Prof. Dr. A. J. KLuYver. 


\section{De plannen van het Nederlandsche Herdenkingscomité}

omvatten :

$1^{\circ}$. Het houden van een Nederlandschen Pasteurdag, op 25 November 1922, te Amsterdam.

$2^{\circ}$. Het opwekken tot plaatselijke herdenkingen.

$3^{\circ}$. Het bijeenbrengen van een Nederlandsche bijdrage tot het in 1923 op te richten PASTEUR monument te Straatsburg. 


\section{Nederlandsche Pasteurdag.}

\section{EERE COMITÉ:}

Jhr. Mr. Dr. H. A. van Karnebeek, Minister van Buitenlandsche Zaken.

Ch. Benoist, Gezant van Frankrijk te 's-Gravenhage.

JHR. Dr. J. Loudon, Hr. M's gezant te Parijs.

JHR. Mr. DR. A. RöEll, Commissaris der Koningin voor Noord-Holland.

W. DE Vlugt, Burgemeester van Amsterdam.

\section{ALGEMEEN COMITÉ:}

Vertegenwoordigers van Akademies, Universiteiten en Hoogescholen, Genootschappen, Vereenigingen, enz.

Kon. Akademie van Wetenschappen te Amsterdam.

Prof. Dr. F. A. F. C. Went, Prof. Dr. L. Bolk.

Universiteit van Amsterdam.

Prof. Dr. P. Zeeman, Prof. Dr. P. Ruitinga.

Vrije Universiteit te Amsterdam.

Prof. Dr. L. Bouman, Mr. P. A. Diepenhorst.

Rijks-Universiteit te Groningen.

Prof. A. Klein,

Prof. DR. H. J. BACKer.

Rijks-Universiteit te Leiden.

Prof. Dr. J. J. Blanksma, Prof. R. P. van Calcar, Prof. DR. D. A. DE Jong.

Rijks-Universiteit te Utrecht.

Technische Hoogeschool te Delft.

PRof. DR. H. J. LAMÉRIS.

Prof. L. A. van Rooljen, Prof. Feldman.

Veeartsenijkundige Hoogeschool te Utrecht.

Prof. Dr. G. Krediet, Prof. Dr. J. E. W. Ihle.

Landbouw Hoogeschool te Wageningen.

Prof. Dr. N. L. Söhngen, Prof. Dr. S. C. J. Olivier. 
Hollandsche Maatschappij van Wetenschappen te Haarlem.

PROF. DR. H. A. LORENTZ.

Gezondheidsraad te 's Gravenhage.

DR. N. M. Josephus JiTTA.

Kon. Instituut van Ingenieurs te 's Gravenhage.

Prof. IR. S. G. Everts.

Genootschap t. b. d. Natuur-, Genees- en Heelkunde te Amsterdam.

Prof. Dr. Ed. Verschaffelt.

Provinciaal Utrechtsch Genootschap van Kunsten en Wetenschappen.

DR. N. J. SingeIS.

Bataafsch Genootschap der Proefondervinderlijke Wijsbegeerte te Rotterdam.

Dr. S. Birnie.

Zeeuwsch Genootschap der Wetenschappen te Middelburg.

DR. D. SCHOUTE.

Natuur- en Geneeskundig Congres.

Dr. D. Coelingh.

DR. E. C. KERBERT.

Ver. v. d. Geschiedenis der Genees-, Wis- en Natuurkunde.

Prof. E. C. van LeERSum.

Nederlandsche Chemische Vereeniging.

DR. G. H. Voerman

Nederlandsche Maatschappij tot bevordering der Pharmacie.

A. F. F. M. VAN den DRIES.

Nederlandsche Vereeniging voor Mikrobiologie.

PRoF. Dr. N. L. Söhngen.

Nederlandsche Phytopathologen Vereeniging.

Dr. H. W. Heinsius.

Nederlandsche Mycologische Vereeniging.

K. BoEdiJn.

Ned. Maatschappij tot bevordering der Geneeskunst.

DR. H. Aldershoff.

Ned. Vereeniging voor Heelkunde.

Ned. Centr. Ver. tot bestr. der Tuberculose.

DR. J. H. KUYJER.

Ned. Alg. Ziektekundige Vereeniging.

DR. H. J. KyLSTRA.

Ned. Vereeniging van tropische Geneeskunde

DR. D. KLINKERT.

Prof: G. J. W. Koolemans Beynen.

Nederlandsch Congres voor Openbare Gezondheidsregeling.

DR. M. L. Roodenburg. 
Maatschappij voor Dierengeneeskunde.

Dr. H. A. Vermeulen.

Ned. Maatschappij tot bevordering der Tandheelkunde.

A. L. J. C. v. Hasselt.

Ned. Botanische Vereeniging.

Ned. Dierkundige Vereeniging.

Ned. Entomologen Vereeniging.

Prof. Dr. G. van Iterson.

Prof. Dr. J. F. van Bemmelen.

Prof. Dr. J. C. H. de Meyere.

Ned. Natuur-Historische Vereeniging.

DR. H. W. HEInSiUs.

Chemisch Weekblad.

DR. W. P. JORISSEN.

Pharmaceutisch Weekblad.

Nederl. Tijdschrift voor Geneeskunde.

Nederlandsche Brouwersbond,

Prof. P. v. D. Wielen.

ARts P. Muntendam.

Camille J. J. Harten.

Vereeniging van de Nederl. Chem. Industrie.

Prof. G. Hondius Boldingh.

Vereeniging van Nederl. Wijnhandelaren.

W. R. FERWERda.

Vereeniging voor Zuivelindustrie en Melkhygiene.

G. J. BLINK.

Alg. Nederl. Zuivelbond.

Dr. F. E. Posthuma.

Overige Leden (voor zoover niet reeds vermeld onder „Vertegenwoordigers):

Prof. Dr. J. H. ABERSon.

DR. H. P. BaRENDRECHT.

DR. C. E. Benjamins.

Prof. Dr. A. Hymans van den BERGH.

PRof. DR. J. BöSEKEN.

DR. L. P. DE BUSSY.

Prof. Dr. F. Hondius Boldingh.

Prof. Dr. A. van BiJlert.

DR. E. H. BÜCHNER.

DR. J. P. BIJL.

DR. F. W. J. BOEKhoudt.

Prof. Dr. E. COHEN.
Dr. W. van Dam.

Prof. Dr. L. Polak Daniels.

Dr. C. C. Delprat.

IR. A. H. van Del.den

ARTS C. ElDERS.

DR. F. C. GeRritsen.

Prof. Dr. L. Goester

DR. E. GORTER.

Mej. Dr. M. A. van Herwerden.

Dr. B. J. C. TE HENNEPE.

DR. J. J. HeKman.

DR. L. Heyermans.

DR. M. D. HORST. 
Prof. Dr. J. A. Honing.

Prof. Dr. A. T. Holleman.

Prof. Dr. G. GriJns.

IR. H. C. JACOBSEN.

Prof. Dr. R. de Josselin dE Jong.

ProF. DR. C. H. KuHN.

Prof. Dr. W. A. Kuenen.

DR. G. KaPSENBERG。

Prof. Dr. J. A. Korteweg.

Dr. C. W. G. Mieremet.

Prof. Dr. H. M. Quanjer.

DR. R. H. Rochat.

DR. H. G. Ringeling.

DR. E. VAN RiJSSEL.

JONKVR. M. VAN RIEMSDIJK.

Prof. Dr. G. van RiJnberk.

Prof. Dr. P. VAN Romburgh.

Prof. Dr. J. Rotgans.

DR. Y. RODENHUIS.

Prof. Dr. H. Schornagel.

DR. S. L. SCHOUTEN.
Prof. Dr. J. G. Sleeswijk.

Prof. Dr. I. Snapper.

Dr. JAN SMIT.

PRoF. DR. A. SMITS.

Dr. F. A. SChaly.

Prof. Dr. A. Schreinemaker.

Prof. Dr. W. A. SCHÜFFner.

DR. M. STRÄTER.

DR. C. S. STOKvis.

PROF. DR. N. SCHOORL.

DR. J. T. TERBURGh.

Prof. Dr. W. M. dE VRIES.

DR. I. H. J. Vos.

DR. W. T. DE VOGEL.

Dr. P. Vermeulen.

Prof. I. Waterman.

Prof. P. van der Wielen.

DR. J. P. Wibaut.

MeVr. Dr. Wibaut - ISEBreE Moens.

Prof. Dr. W. P. C. Zeeman.

Prof. DR. J. P. Kleiweg de ZwaAn.

\section{REGELINGSCOMITÉ:}

Prof. Dr. J. J. Salverda de Grave, Voorzitter.

Mr. G. L. DE VRies Feijens, Secretaris.

Mej. Jeanne Scheffer.

A. Melchior, Rector van het Amst. Studenten-Corps.

J. E. Prakken, Rector der Unitas Stud. Amst.

Mej. C. Ledeboer, Voorzitster der Amst. Vrouw. Stud. Ver.

J. C. V. Cohen, Voorzitter van de R. K. Stud. Ver. „Sanctus Thomas Aquinas".

\section{TENTOONSTELLINGSCOMITÉ:}

Prof. Dr. J. J. van Loghem, Voorzitter. JonkVR. M. VAn RiEmsdiJK, Secretaresse.

IR. H. J. L. DONKER.

A. van Itallie.

Prof. Dr. A. J. Kluyver.

J. G. A. Weisenborn.

Dr. J. P. Wibaut.

ARTS L. K. WolfF. 


\section{Programma van den Nederlandschen Pasteurdag op 25 November 1922.}

I Herdenkingsplechtigheid des namiddags 3 uur in het Concertgebouw te Amsterdam.

1e Opening door den Voorzitter van het uitvoerend comité, Prof. Dr. J, J. VAN Loghem.

2e Herdenking van Louis PAsteur, van scheikundig standpunt door PROF. DR. F. M. JAEger (Groningen);

van technisch mikrobiologisch standpunt door PROF. DR. A. J. Kluyver (Delft);

van ziektekundig standpunt door Prof. DR. C. H. H. SPRONCK (Utrecht).

3e Rede van Prof. Dr. Calmette (Parijs).

"L'oeuvre de Pasteur et son influence sur les progrès de la civilisation."

II Openbare Pasteurmaaltijd, des avonds 7 uur in Restaurant „Trianon”, Leidscheplein 31, Amsterdam, onder voorzitterschap van Prof. Dr. J. J. Salverda de Grave.

\section{Pasteur-Tentoonstelling}

in het Laboratorium voor Gezondheidsleer der Universiteit, Mauritskade 57 (ingang Oosterpark) Amsterdam, van Z $\mathrm{Zndag}$ 26 November tot en met Zondag 3 December, geopend van $11^{1 / 2}-5$ uur (des Zondags) en van 2-5 uur (de weekdagen). 


\section{Plaatselijke Herdenkingen.}

Rotterdam op 25 November, voorbereid door een comité bestaande uit Mr. A. R. Zimmerman, Eere-Voorzitter, Dr. Med. J. Hekman, Voorzitter, Arts F. A. Schaly, Secretaris, Dr. Chem. A. J. BoKs, Dr. IR. D. P. Hoyer en Dr. Pharm. A. Robertson, Apotheker.

Sprekers: Prof. Dr. E. Cohen en Prof. Dr. D. A. DE Jong.

Rotterdam op 26 November, voorbereid door de Afdeelingen Rotterdam der „Alliance Française” en van het Genootschap „Nederland-Frankrijk”.

Spreker: Prof. Dr. A. Calmette.

Leiden op 27 November, voorbereid door de Leidsche Vereeniging voor Wetenschappelijke Voordrachten.

Spreker: Prof. Dr. A. CalmetTe.

Utrecht op 28 November, voorbereid door het Provinciaal Utrechtsch Genootschap van Kunsten en Wetenschappen en de Studenten-Organisaties.

Spreker: Prof. Dr. A. Calmette.

Wageningen op 2 December, voorbereid door de Nederlandsche Vereeniging van Mikrobiologie.

Sprekers: Prof. Dr. N. L. Söhngen en Prof. Dr. D. A. DE JONG.

Den Haag op 23 December, voorbereid door de Nederlandsche Natuur-Historische Vereeniging en de Maatschappij Diligentia aldaar.

Spreker: DR. A. SCHIERBEEK.

Delft, op nader vast te stellen datum, voorbereid door een comité bestaande uit DR. F. G. Waller, Voorzitter, Dr. H. P. Barendrecht, Prof. Dr. J. Böseken, Prof. Dr. G. van Iterson, Prof. Dr. A. J. Kluyver, Secretaris 
en de Voorzitters van den Delftschen Chemischen Kring, het Technologisch Gezelschap en de Delftsche Studenten-NatuurWetenschappelijke Vereeniging, "Christiaan Huygens”, de heeren IR. C. J. SNiJders, F. VisSER 'T Hooft en C. E. VAN DE STADT.

Spreker: Dr. G. Bertrand (Parijs).

Middelburg, op 6 December, voorbereid door het Zeeuwsch Genootschap der Wetenschappen aldaar.

Spreker: Prof. Dr. J. J. VAN Loghem.

Zutfen, op nader vast te stellen datum, voorbereid door het Natuurkundig Genootschap, aldaar.

Spreker: ARTs L. K. WOLFF.

Assen, op 14 December, voorbereid door de Afdeeling der Ned. Maatschappij t. b. d. Geneeskunst aldaar.

Spreker: Prof. DR. J. J. VAN Loghem. 

Q Louis Pasteur

143

P2L6

Physical *

Applied Sci.

PLEASE DO NOT REMOVE CARDS OR SLIPS FROM THIS POCKET

UNIVERSITY OF TORONTO LIBRARY 
